\title{
Improving the Performance of Reprocessed ABS Products from the Manufacturing Perspective via the Taguchi Method
}

\author{
Ng Chin Fei, ${ }^{1}$ Nik Mizamzul Mehat, ${ }^{1,2}$ Shahrul Kamaruddin, ${ }^{1}$ and Zulkifli Mohamad Ariff ${ }^{3}$ \\ ${ }^{1}$ School of Mechanical Engineering, Universiti Sains Malaysia, Engineering Campus, 14300 Nibong Tebal, Penang, Malaysia \\ ${ }^{2}$ Department of Mould Technology, Kolej Kemahiran Tinggi MARA, Balik Pulau, Genting, 11000 Balik Pulau, Penang, Malaysia \\ ${ }^{3}$ School of Materials and Mineral Resources Engineering, Universiti Sains Malaysia, Engineering Campus, 14300 Nibong Tebal, \\ Penang, Malaysia
}

Correspondence should be addressed to Shahrul Kamaruddin; meshah@eng.usm.my

Received 12 June 2013; Accepted 29 October 2013

Academic Editors: A. Lockamy, K. Salonitis, J. Tamaki, and H. Yu

Copyright (C) $2013 \mathrm{Ng}$ Chin Fei et al. This is an open access article distributed under the Creative Commons Attribution License, which permits unrestricted use, distribution, and reproduction in any medium, provided the original work is properly cited.

\begin{abstract}
Additives are costly and can have negative environmental effects. Thus, searching for other alternatives to improve recycling plastics without using additives is necessary. This study aims to improve the hoop tensile strength, elongation at break, and shrinkage of the ring stopper made from an acrylonitrile butadiene styrene blend comprising $40 \%$ recyclates through the optimization of processing parameters using the Taguchi method. By adopting the $L_{9}$ Taguchi orthogonal array, four controllable factors each at three levels are tested to determine the optimal combination of factors and levels in the injection moulding process. Considering the multiple quality characteristics involved in this study, we investigate the effects of processing parameters on hoop tensile strength, elongation at break, and shrinkage of the ring stopper both separately and simultaneously because changing a parameter can result in the improvement or deterioration of each quality response and of the overall product performance. The results revealed that the performance of an injection-moulded ring stopper under the optimal process conditions is equivalent or slightly better than that of the part produced from virgin resin. The performance of recycled plastics can be effectively enhanced to levels comparable with virgin resins using the Taguchi optimization approach.
\end{abstract}

\section{Introduction}

Plastics have entrenched themselves within the spectrum of modern materials as approximately $16 \%$ of applications are designed with plastics, which cannot be feasibly substituted. A world without plastics is difficult to imagine as plastic products have infiltrated every corner of human life, from the morning toothbrush to the garbage bag that is carried out at the end of the day. However, high plastic consumption inexorably causes an increasing amount of plastic to end up in the waste stream. Relative to population growth and along with the significant influx of foreign workforce to cities, the problem of plastic waste tends to be more severe in developing countries, such as Malaysia. Given their nonbiodegradability and high visibility in the waste stream, plastic waste can persist for at least decades and probably for centuries, resulting in serious pollution problems. Therefore, a sustainable plastic waste management strategy must be established to manage the large amount of generated plastic waste. The large-scale practice of plastic recycling can be conducted on a multitude of products, ranging from consumer commodities, such as soft drink bottles [1], to industry applications, such as automobile components [2]. Nevertheless, plastic recycling remains hindered by a wide range of barriers, including restrictions imposed by standards and specifications, as well as mistrust of the quality assurance of recycled plastics. Most plastic manufacturers and consumers are reluctant to use recycled plastics because of the perception that recycled plastics are inferior to virgin resin and that the use of recyclates will result in mediocre performance in their products [3]. This perception stems from the fact that polymeric materials are submitted to successive cycles of 
high temperature and intensive shear stress during multiple reprocessing, thus resulting in a deterioration in their physical properties and functional quality [4]. Thermomechanical degradation induces chain scissions of the polymeric chains because of the effect of the radical chain reaction, which gives rise to a series of modifications in the structural and macroscopic properties of the polymers [5]. Thus, the quality of recycled plastics intended for reprocessing is determined by the history of recyclate synthesis. The number of reprocessing operations significantly affects the extent of degradation, which in turn influences the mechanical and rheological properties of recycled products $[6,7]$. To improve recycled plastics to a comparable standard with virgin materials, most works emphasize the development of a suitable technology for the recycling and improvement of the properties of recyclates.

Additives, including stabilizers, fillers, and compatibilizers, are typically added to recycled resins, and each type of additive demonstrates different functional uses in enhancing the properties of recyclates [8]. Stabilizers do not effectively recover the recyclates but are used to protect the recyclates from thermomechanical degradation during reprocessing while extending the longevity of the material [9]. The processability and tensile properties of recyclates can be reinforced by using fillers [10]. However, a critical weakness of fillers is that impact strength and elongation at break are simultaneously decreased with filler reinforcement [11, 12]. In another study, Phuong et al. [13] used maleic anhydride grafted polypropylene as a compatibilizer to improve the properties of recycled PP/organoclay nanocomposites. As a result, impact and tensile strength increased by $36 \%$ and $40 \%$, respectively, with the addition of $20 \mathrm{wt} \%$ of compatibilizers. The different functionalities of additives to tailor the properties of recyclates allow for more versatile uses with a vast array of applications.

In reference to the reviewed literature, most works on plastic recycling only focused on the improvement of the properties of recycled plastics from the material perspective by using additives. Nevertheless, the cost of additives is a major consideration of plastic manufacturers because of the need to bear an additional manufacturing cost regardless of the effectiveness of additives in improving recyclates [14]. Thus, another consideration arises from the manufacturing perspective to improve the performance of recycled plastic products. Process optimization is found to have a decisive effect on the quality improvement of injection-moulded parts, but its influence is grossly underestimated. Numerous studies were conducted to investigate the influence of injection moulding parameters on the mechanical properties of moulded parts and on the occurrence of moulding defects [15-17]. The findings showed a strict correlation between processing parameters and the quality of the injectionmoulded parts, where an optimal combination of processing parameters significantly improves the quality of parts. By contrast, improper setting of processing parameters may cause serious defects, such as warpage, shrinkage, sink mark, and residual stress [18].

Therefore, controlling all the influencing factors during the manufacturing process using an appropriate optimization method, such as the Taguchi method, is essential. The Taguchi method has recently become a widely accepted technique for optimizing processes and improving the quality of parts. Shi et al. [19] employed the Taguchi method to optimize process conditions, including mould temperature, melt temperature, injection time, and injection pressure, to establish a soft computing model with minimum shear stress. The result showed that the maximum shear stress was significantly reduced by $24.9 \%$ after the optimization of process conditions. Kurtaran et al. [20] reduced the warpage of an injection-moulded bus ceiling lamp base by $46.5 \%$ with the optimum values of processing parameters, including mould temperature, melt temperature, packing pressure, packing pressure time, and cooling time. Another study with a similar aim, conducted by Ozcelik and Erzurumlu [21], also indicated that the optimal combination of processing parameters managed to reduce the warpage of the initial thin shell plastic model significantly by $51 \%$. However, publications on the optimization of injection moulding conditions, particularly for recycled plastics, are scarce. Therefore, to maximize the potential of recyclates in high-value applications, this study emphasizes the optimization of processing parameters for reprocessed acrylonitrile butadiene styrene (ABS) using the Taguchi method as an alternative solution to improve the properties of recycled plastics.

This paper emphasizes the effects of processing parameters on hoop tensile strength, elongation at break, and shrinkage of ring stopper produced from an ABS blend comprising $40 \%$ recycled plastics without the addition of stabilizers, fillers, or compatibilizers. The Taguchi method is used to optimize the processing parameters to improve the performance of the ring stopper. An $L_{9}$ orthogonal array is used in the experimental design for the four controllable parameters, including melt temperature, packing pressure, injection time, and packing time, each at three levels, to determine the optimal combination of factors and levels in the injection moulding process. The effects of processing parameters on the hoop tensile strength, elongation at break, and shrinkage of the ring stopper are also investigated. A sideby-side comparison of product performance was conducted for ring stoppers produced from $100 \%$ virgin resins and ABS blend comprising $40 \%$ recyclates before and after optimization to determine the feasibility of improving the recycled plastics from the manufacturing perspective and to verify the effectiveness of the Taguchi method.

\section{Experimental Methods}

2.1. Part Description. In this study, a ring stopper with dimensions of $40 \mathrm{~mm}$ outer diameter, $32 \mathrm{~mm}$ inner diameter, and $9.3 \mathrm{~mm}$ height is used in the experiment (Figure 1).The ring stopper is designed such that it can hold a metal yoke, which will be pressed into the holder to form a steadfast grip with an interference fit. Therefore, to create an interference fit, a high degree of tightness is required for the ring stopper to grip the metal yoke. In other words, the diameter of the metal yoke has to be slightly larger than that of the holder. 


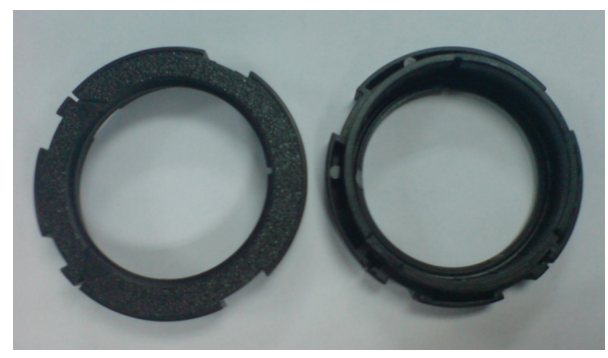

Figure 1: Ring stopper.
TABLE 1: General properties of ABS Novodur P2MT.

\begin{tabular}{lc}
\hline Properties & \\
\hline Density $\left(\mathrm{kg} / \mathrm{mm}^{3}\right)$ & 1.04 \\
Melt flow index $\left(220^{\circ} \mathrm{C} / 10 \mathrm{~kg}\right)$ & 8 \\
Ultimate tensile strength $(\mathrm{MPa})$ & 48 \\
Tensile strain $(\%)$ & 2.4 \\
Modulus of elasticity $(\mathrm{GPa})$ & 2.5 \\
Izod/RT, notched $(\mathrm{J} / \mathrm{m})$ & 220 \\
Hardness $(\mathrm{HK})$ & 100 \\
\hline
\end{tabular}

The application of the ring stopper will cause the hoop tensile properties to be a direct reflection of product quality for end use. A hard and tough material would be capable of absorbing enormous amounts of energy, particularly when high hoop tensile strength and high elongation at break are desired for a product to sustain the tensile stress created by the metal yoke against its interior wall and consequently prevent structural failure. Aside from hoop tensile properties, dimensional stability is also a crucial quality issue to be evaluated. The shrinkage of the ring stopper will increase the degree of tightness, which will increase the probability of cracking because of dimensional deformation. Therefore, the hoop tensile strength, elongation at break, and shrinkage of the ring stopper will be evaluated in this study.

2.2. Materials. The ABS material was of injection grade, denoted as Novodur P2MT, and supplied by Lanxess. The material was used as received. The general properties of virgin ABS are shown in Table 1.

The recycled ABS pellets are of the same grade as the virgin material and were sourced by crushing existing products and postindustrial scraps using a granulator. In this study, the recycled ABS pellets were subjected to 10 reprocessing cycles, and a blending compound, known as R-40, was prepared by mixing ratios of $40 \%$ (by volume) of 10 -time-reprocessed ABS with the virgin resins with a proportional mixing valve, Motan Metromix 38, supplied by Motan-Colortronic Ltd., UK.

2.3. Experimental Parameters and Design. A preliminary experiment was conducted using Cadmould 3D-F to determine the values of the processing parameters necessary to produce a part without any aesthetic defect, such as short shot, flash, sink mark, and silver streaks. Based on the simulation results, the appropriate values of the processing parameters were set. Using two progressive strokes in the packing process was found to reduce the probability of sink mark defects significantly. The optimization experiment was conducted using an Arburg injection moulding machine model 270 M Allrounder 350-90 (Germany). Four processing parameters, namely, melting temperature (a), packing switchover (b), injection pressure (c), and packing pressure at second stroke (d), were selected for optimization with the aim of enhancing the hoop tensile strength, elongation at break, and shrinkage of reprocessed ABS products. Other parameters, such as mould temperature $\left(60^{\circ} \mathrm{C}\right)$, packing pressure at

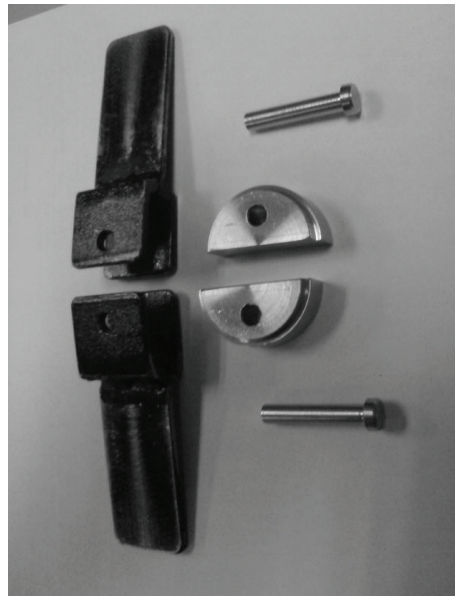

Figure 2: Split disk test fixture.

first stroke (600 bars), packing time at first and second strokes ( 2 and $3 \mathrm{~s}$ ), cooling time ( $10 \mathrm{~s})$, and stroke distance $(200 \mathrm{~mm})$, were kept constant during the experiment. Table 2 shows the layout of $L_{9}$ orthogonal array (OA) in the experiment design.

Referring to Table 2, the processing parameters, and their effects on the performance characteristics, each parameter was set at three levels which are levels 1,2 , and 3, respectively. In this case, level 2 of each processing parameters are the actual values implemented in producing the ring stoppers by the company where the research has been conducted. Therefore, the values of all processing parameter at level 2 is used as the baseline in selecting of level 1 and level 3 in the optimization experiment.

\subsection{Quality Testing}

2.4.1. Hoop Tensile Test. Considering the limitations of the dimension and shape of the component, the hoop tensile strength and elongation at break were measured in accordance with ASTM D2290-04 using an Instron 3367 series table-mounted universal testing machine. A split-disc test fixture was fabricated accordingly, as shown in Figure 2. The test specimen was mounted on the test fixture, where the reduced sections were placed at the side of split, thus ensuring that the specimen was centered on the line joining the fixture's points of attachment with the test machine (refer to Figure 3). The crosshead speed was $2.54 \mathrm{~mm} / \mathrm{min}$, and five specimens were tested for each reprocessing cycle. 
TABLE 2: Design of experiment using $L_{9}$ orthogonal array.

\begin{tabular}{lcccc}
\hline Trial no. & $\begin{array}{c}\text { A: melting } \\
\text { temperature }\left({ }^{\circ} \mathrm{C}\right)\end{array}$ & $\begin{array}{c}\text { B: packing } \\
\text { switchover }(\%)\end{array}$ & $\begin{array}{c}\text { C: injection } \\
\text { pressure (bar) }\end{array}$ & $\begin{array}{c}D: \text { packing } \\
\text { pressure-stroke 2 (bar) }\end{array}$ \\
\hline 1 & 240 & 75 & 1400 & 600 \\
2 & 240 & 80 & 1500 & 700 \\
3 & 240 & 85 & 1600 & 800 \\
4 & 250 & 75 & 1500 & 800 \\
5 & 250 & 80 & 1600 & 600 \\
6 & 250 & 85 & 1400 & 700 \\
7 & 260 & 75 & 1600 & 700 \\
8 & 260 & 80 & 1400 & 800 \\
9 & 260 & 85 & 1500 & 600 \\
\hline
\end{tabular}

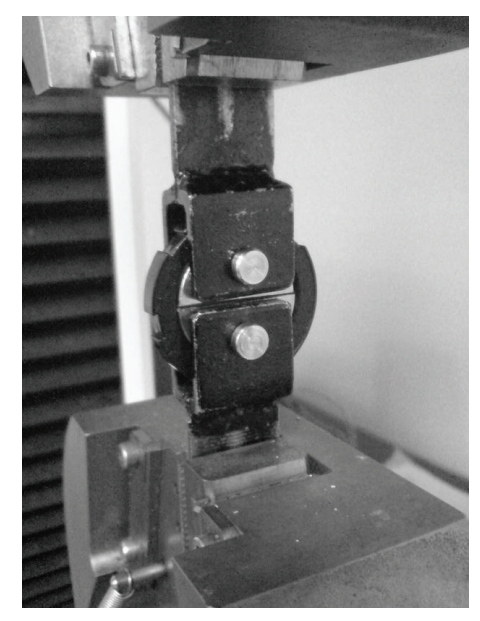

FIGURE 3: Setup of split disk test fixture.

The hoop tensile strength at yield of the specimens was calculated using the appropriate equation, as stated in ASTM D2290-04, as follow:

$$
\sigma_{a}=\frac{P_{b}}{\left(d_{1} b_{1}+d_{2} b_{2}\right)},
$$

where $\sigma_{a}$ is the hoop yield or ultimate tensile stress of the specimen $(\mathrm{MPa}), P_{b}$ is the maximum or breaking load $(\mathrm{N})$, $d_{1}, d_{2}$ are the thicknesses at the reduced or test section $(\mathrm{mm})$, and $b_{1}, b_{2}$ are the widths of the reduced or test section ( $\mathrm{mm}$ ).

Conversely, the elongation at break of the specimens was computed by taking the percentage of the elongated displacement at maximum load over the inner diameter of the test specimen as follows:

$$
e_{z}=\frac{\left(l_{z}-l_{o}\right)}{l_{o}} \times 100 \%,
$$

where $e_{z}$ is elongation at break in percentage, $l_{z}$ is the final length of the specimen after the hoop tensile test, and $l_{o}$ is the original length of the specimen.

2.4.2. Shrinkage Test. Rax Vision DC 3000 Mitutoyo profile projector (Japan) was used to measure the outer diameter
TABLE 3: The optimization experimental results for ring stopper.

\begin{tabular}{lccccccc}
\hline \multirow{2}{*}{ Trial no. } & \multicolumn{4}{c}{ Factor } & \multicolumn{3}{c}{ Result } \\
& $A$ & $B$ & $C$ & $D$ & $X(\mathrm{MPa})$ & $Y(\%)$ & $Z(\%)$ \\
\hline 1 & 240 & 75 & 1400 & 600 & 49.701 & 3.829 & 0.184 \\
2 & 240 & 80 & 1500 & 700 & 50.333 & 3.772 & 0.052 \\
3 & 240 & 85 & 1600 & 800 & 49.307 & 3.832 & 0.015 \\
4 & 250 & 75 & 1500 & 800 & 49.486 & 3.831 & 0.075 \\
5 & 250 & 80 & 1600 & 600 & 49.636 & 3.759 & 0.005 \\
6 & 250 & 85 & 1400 & 700 & 48.506 & 3.731 & 0.147 \\
7 & 260 & 75 & 1600 & 700 & 48.392 & 3.768 & 0.116 \\
8 & 260 & 80 & 1400 & 800 & 48.405 & 3.758 & 0.160 \\
9 & 260 & 85 & 1500 & 600 & 48.008 & 3.688 & 0.133 \\
\hline
\end{tabular}

of the part. The profile projector was also used to measure the two-dimensional contours of the specimens. With large magnifications and micrometer readouts, this profile projector could ensure fairly accurate measurements compared with a Vernier caliper and micrometer. The geometrical measurement was performed using a micrometer with the aid of a magnifier lens at 10x magnification using diascopic illumination. To ensure the integrity of the comparison procedure, four injection-moulded parts that came from the same batch were measured to determine the repeatability of the part geometry. Finally, the relative shrinkage of the part was calculated using the following equation:

$$
S=\frac{\left(D-D_{m}\right)}{D_{m}} \times 100 \% \text {, }
$$

where $S$ is shrinkage, $D$ is the reading of diameter measurement using profile projector, and $D_{m}$ is the mould dimension.

\section{Results and Discussion}

3.1. Analysis of Signal-to-Noise (S/N) Ratio and Data Normalization. In this study, nine combinations of parameters and levels based on Taguchi's $L_{9}$ OA are conducted in the optimization experiment. The experimental results of hoop tensile strength $(X$ in $\mathrm{MPa}$ ), elongation at break ( $Y$ in \%), and shrinkage ( $Z$ in \%) are listed in Table 3. 
TABLE 4: $S / N$ ratios and data normalization of optimization results.

\begin{tabular}{lccccccc}
\hline \multirow{2}{*}{ Trial no. } & \multicolumn{3}{c}{$S / N$ ratio $(\mathrm{dB})$} & \multicolumn{4}{c}{ Normalized } \\
& $X$ & $Y$ & $Z$ & $X$ & $Y$ & $Z$ & $C$ \\
\hline 1 & 33.927 & 11.662 & 14.715 & 0.733 & 0.981 & 0.000 & 1.714 \\
2 & 34.037 & 11.530 & 25.666 & 1.000 & 0.586 & 0.350 & 1.936 \\
3 & 33.858 & 11.668 & 36.723 & 0.565 & 1.000 & 0.703 & 2.268 \\
4 & 33.890 & 11.665 & 22.499 & 0.641 & 0.991 & 0.249 & 1.881 \\
5 & 33.916 & 11.502 & 46.021 & 0.705 & 0.502 & 1.000 & 2.207 \\
6 & 33.716 & 11.436 & 16.673 & 0.218 & 0.303 & 0.063 & 0.584 \\
7 & 33.695 & 11.523 & 18.692 & 0.168 & 0.562 & 0.127 & 0.858 \\
8 & 33.698 & 11.498 & 15.918 & 0.174 & 0.489 & 0.038 & 0.701 \\
9 & 33.626 & 11.335 & 17.501 & 0.000 & 0.000 & 0.089 & 0.089 \\
\hline
\end{tabular}

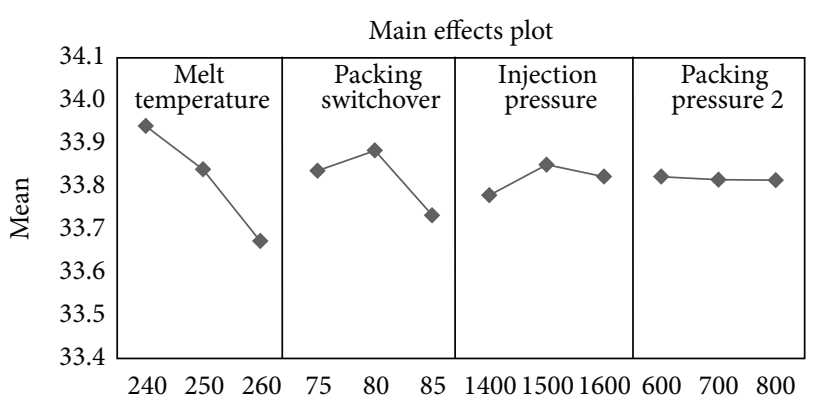

FIGURE 4: Diagram of main effects for hoop tensile strength.

The experimental results (Table 3) were evaluated in terms of $S / N$ ratio, which was calculated using Microsoft Excel software. A ring stopper with large hoop tensile strength, elongation at break, and small shrinkage is desired. Therefore, the-higher-the-better $S / N$ ratio formula is chosen for hoop tensile strength and elongation at break, whereas an equation describing the-lower-the-better characteristic is used for the shrinkage analysis. The formulas of $S / N$ ratio are shown in (4) and (5).The higher the better:

$$
\frac{S}{N}=-10 \log \frac{1}{n} \sum \frac{1}{y^{2}}
$$

The lower the better:

$$
\frac{S}{N}=-10 \log \frac{1}{n} \sum y^{2},
$$

where $y$ denotes the experimental result and $n$ refers to the number of repetitions

Owing to multiple quality characteristics involved in this study, analyzing the effect of processing parameters on hoop tensile strength, elongation at break, and shrinkage simultaneously is practical. The $S / N$ ratios are subsequently converted into normalized values ranging from 0 to 1 , and the summation of the normalized values results in a unit value that represents multiple quality characteristics of the ring stopper.

Table 4 shows that the $S / N$ ratio for hoop tensile strength, elongation at break, and shrinkage was transformed into a commensurable value between 0 and 1 to represent the desired level of satisfaction for the quality characteristic

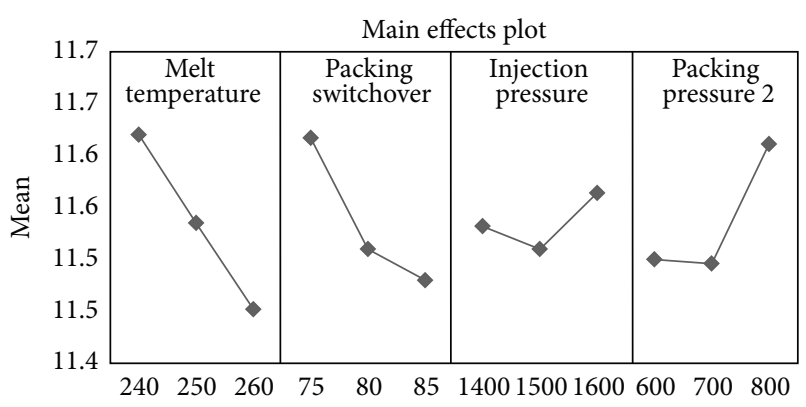

FIGURE 5: Diagram of main effects for elongation at break.

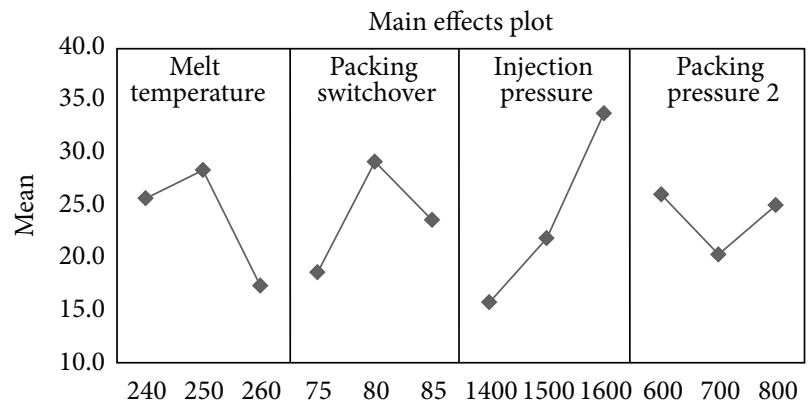

FIGURE 6: Diagram of main effects for shrinkage.

with the ratio. The summation of the normalized values $X$, $Y$, and $Z$ representing hoop tensile strength, elongation at break, and shrinkage, respectively, is computed and given the same importance to result in a combined value $(C)$. These quality characteristics are combined to study the effect of processing parameters on multiple quality characteristics simultaneously instead of focusing on a single quality characteristic. Considering that the combined value is the response for multiple quality characteristics, a higher combined value indicates that the ring stopper possesses the maximum hoop tensile strength, elongation at break, and minimum shrinkage concurrently.

3.2. Main Effects Analysis. Different processing parameters have different effects on quality responses, and changing a parameter can improve or degrade product quality. The main effects of processing parameters on hoop tensile strength, elongation at break, and shrinkage are computed individually and presented in a graphical display in Figures 4, 5, and 6 to demonstrate the effect of individual quality characteristics of the ring stopper on the adjustments of processing parameters. Figure 4 shows that a lower melt temperature imparts a good quality characteristic in terms of hoop tensile strength, as higher melt temperature reduces molecular orientation because of molecular relaxation after the cessation of flow [22]. A low degree of molecular orientation imparts inferior tensile strength to the final product. In addition, Wang et al. [23] stated that tensile strength decreases with increasing melt temperature because shear stress induces orientation at high melt temperature. Conversely, higher hoop tensile strength is observed at level 2 for the parameters of packing 


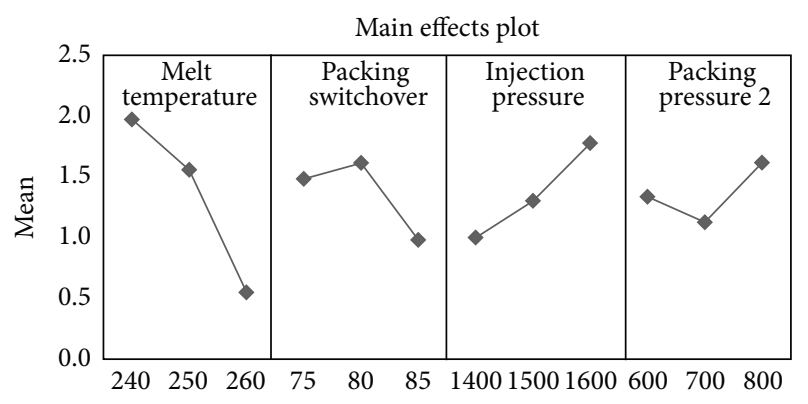

FIGURE 7: Diagram of main effects for multiple quality characteristics.

switchover and injection pressure. The packing pressure at second stroke has slightly better hoop tensile strength at level 1 , but the variation is insignificant. The parameter levels that will generate the largest hoop tensile strength are a melt temperature of $240^{\circ} \mathrm{C}$, packing switchover of $80 \%$, injection pressure of $1500 \mathrm{bar}$, and packing pressure at second progressive stroke of 600 bar.

Considering a single quality characteristic in terms of elongation at break, two opposite trends are observed in Figure 5, where the elongation at break of the ring stopper is higher when the melt temperature and packing switchover decrease. The result is in line with the study of Zhang et al. [24], where an increase in melt temperature decreased the elongation at break. By contrast, the increment of injection pressure and packing pressure at the second progressive stroke will enhance the elongation at break. As a result, the combination of melt temperature of $240^{\circ} \mathrm{C}$, packing switchover of $75 \%$, injection pressure of 1600 bar, and packing pressure at second progressive stroke of 800 bar results in the best performance for elongation at break.

Figure 6 shows that the melt temperature and packing switchover exhibit a similar trend, where the maximum mean response is found at level 2. Conversely, a higher injection pressure results in better quality characteristics. The result matches the earlier findings of Chang and Faison [25], where the higher injection pressure reduces shrinkage in the along- and across-the-flow directions for ABS plastics. For the packing pressure at second progressive stroke, the mean response at level 1 of the parameter shows the least shrinkage. Therefore, the optimum factor levels that could statistically result in the minimum shrinkage for the injection-moulded ring stopper are a melt temperature of $250^{\circ} \mathrm{C}$, packing switchover of $80 \%$, injection pressure of 1600 bar, and packing pressure at second progressive stroke of 600 bar.

From the main effects analysis (Figures 4, 5, and 6), each quality characteristic is shown to have a different set of optimal process conditions. Thus, using only one set to improve multiple quality characteristics simultaneously is impractical. Therefore, enhancing hoop tensile strength, elongation at break, and shrinkage of the ring stopper simultaneously with only one combination of optimal parameters is crucial. The main effects for the multiple quality characteristics are computed based on the analysis of the combined values. Figure 7 clearly shows that multiple quality characteristics of the ring stopper are significantly influenced by the adjustment of processing parameters. The best combination of parameters and levels could easily be obtained from the main effect analysis by selecting the level of parameter with the highest mean value. As a result, the optimal parameter setting, which statistically results in the maximum hoop tensile strength and elongation at break, as well as minimum shrinkage for the ring stopper, is predicted to be $A_{1} B_{2} C_{3} D_{3}$. As shown by the main effect plot, the optimal parameter setting represents a melt temperature of $240^{\circ} \mathrm{C}, 80 \%$ packing switchover, $1600 \mathrm{bar}$ injection pressure, and 800 bar packing pressure at the second progressive stroke.

3.3. Analysis of Variance (ANOVA). The ANOVA results in Tables 5, 6, 7, and 8 show the individual and simultaneous effects of processing parameters on hoop tensile strength, elongation at break, and shrinkage to assess the significance of the processing parameters on single and multiple quality characteristics. The F-ratio test is used to determine the significance of the processing parameters. A larger value of $F$ indicates that the parameter has greater importance in terms of influencing the process response. However, the $F$-ratio and pure sum of squares cannot be computed in the optimization experiment when the degree of freedom for the error term is equal to zero [26]. As a result, the percentage contribution of each processing parameter is directly calculated from the sums of squares, and the significance of each processing parameter is based on the quality characteristics of the ring stopper that can be determined by the percentage contribution. Roy [27] suggested an alternative using the $10 \%$ rule, which is to consider a parameter insignificant when its influence is less than $10 \%$ of the highest parameter influence. The insignificant parameters should be pooled, and their contributions will not be considered in the projection of the optimum performance. Conversely, the percentage contribution of the significant parameters is recalculated after pooling the insignificant parameters to the error term.

From Table 5, melt temperature is found to be the most significant parameter with the highest percentage contribution of $69.24 \%$, followed by packing switchover at $20.69 \%$. Meanwhile, the percentage contribution of the error term shows $10.07 \%$. The percentage contributions of injection pressure and packing pressure at second progressive stroke are significantly less than $10 \%$ of the highest parameter influence before pooling. Thus, the two insignificant parameters are pooled. In ANOVA, a small percentage contribution of the error term represents weak influence from parameters that are not included in the study or from other noise factors. Therefore, the low percentage contribution of the error term implies that the control parameters are suitably chosen for the experiments.

No insignificant parameter is found to affect the elongation at break of the recycled ABS ring stopper, as shown in Table 6. The percentage contributions of all processing parameters are greater than $10 \%$ of the highest parameter influence contributed by the melt temperature. The melt temperature is the most influential factor in improving the elongation at break of the ring stopper, whereas injection 
TABLE 5: ANOVA table for hoop tensile strength in optimization experiment.

\begin{tabular}{|c|c|c|c|c|c|c|}
\hline Column & Parameter & DOF & Sum of squares & Variance & F & Percent \\
\hline$A$ & Melt temperature & 2 & 0.110 & 0.055 & 28.51 & 69.24 \\
\hline$B$ & Packing switchover & 2 & 0.036 & 0.018 & 9.22 & 20.69 \\
\hline C & Injection pressure & $(2)$ & $(0.008)$ & & Pooled & \\
\hline$D$ & Packing pressure 2 & $(2)$ & $(0.000)$ & & Pooled & \\
\hline & All others/error & 4 & 0.008 & 0.002 & & 10.07 \\
\hline & Total & 8 & 0.153 & & & 100.00 \\
\hline
\end{tabular}

TABLE 6: ANOVA table for elongation at break in optimization experiment.

\begin{tabular}{|c|c|c|c|c|c|c|}
\hline Column & Parameter & DOF & Sum of squares & Variance & $F$ & Percent \\
\hline$A$ & Melt temperature & 2 & 0.042 & 0.021 & & 41.20 \\
\hline$B$ & Packing switchover & 2 & 0.031 & 0.015 & & 29.97 \\
\hline C & Injection pressure & 2 & 0.004 & 0.002 & & 4.29 \\
\hline \multirow[t]{3}{*}{$D$} & Packing pressure 2 & 2 & 0.025 & 0.013 & & 20.29 \\
\hline & All others/error & 0 & & & & \\
\hline & Total & 8 & 0.103 & & 100.00 & \\
\hline
\end{tabular}

pressure has the least contribution with only $4.29 \%$, which slightly exceeds the minimum requirement of the $10 \%$ rule.

Table 7 shows that injection pressure is the most decisive processing parameter in reducing shrinkage defects with the highest percentage contribution of $54.49 \%$, outweighing the other process variables. The analysis results revealed that all processing parameters are significant as their percentage contributions are more than $10 \%$ of the highest parameter influence. The melt temperature and packing switchover achieve $21.39 \%$ and $18.08 \%$, respectively. Meanwhile, packing pressure at second progressive stroke has the lowest percentage contribution at $6.05 \%$ in terms of influencing the shrinkage of the ring stopper.

Table 8 shows that all processing parameters are determined as significant in considering multiple quality characteristics simultaneously. Among the processing parameters selected in the optimization experiment, melt temperature is found to be the principal parameter affecting the hoop tensile strength, elongation at break, and shrinkage of the ring stopper. The relative significance of each processing parameter was arranged in decreasing order of melt temperature $(62.13 \%)$, injection pressure $(17.83 \%)$, packing switchover $(13.01 \%)$, and packing pressure at second progressive stroke (7.03\%). Given that all processing parameters are significant, no result is shown for the error term as the degree of freedom of the error term is zero.

3.4. Comparison of Product Performance before and after Optimization. A side-by-side comparison of product performance was conducted between the ring stoppers produced from $100 \%$ virgin resins and ABS blend comprising $40 \%$ recyclates ( $\mathrm{R}-40)$ before and after optimization to assess the feasibility of improving the performance of recycled plastics to levels comparable with or even better than using virgin resin based on the Taguchi method. Table 9 shows that the overall product performance of $\mathrm{R}-40$ before optimization is more inferior to that of virgin $\mathrm{ABS}$. However, the hoop tensile strength, elongation at break, and shrinkage of the ring stopper produced from R-40 were improved to a higher quality level through the optimization of processing parameters using the Taguchi method.

Table 9 shows that the injection-moulded ring stopper achieves $50.74 \mathrm{MPa}$ of hoop tensile strength, $4.89 \%$ of elongation at break, and $0.0075 \%$ of shrinkage under optimal process conditions, in which the performance is equivalent or slightly better than the part produced using virgin resin. Consequently, the performance of the recycled plastics can be effectively enhanced at levels comparable with virgin resins using the Taguchi optimization approach. The use of postindustrial plastic wastes in production not only decreases the raw material cost but also reduces the adverse effect on the environment. Improving plastic recycling bears no additional processing cost, making plastic recycling commercially and practically viable in the industry.

\section{Conclusions}

This study examined the feasibility of improving recycled plastics from the manufacturing perspective at no additional processing cost for plastic production. Through the optimization of processing parameters using the Taguchi optimization method, the ring stopper produced from an ABS blend comprising $40 \%$ recyclates was successfully improved to a higher quality level that is close to or even better than the ring stopper produced using virgin ABS resin. An optimal solution was determined from the combination of processing parameters that exhibit the largest normalized combined $S / N$ ratio of multiple quality characteristics of the ring stopper. The optimal parameter setting using the Taguchi method was characterized as follows: melt temperature of $240^{\circ} \mathrm{C}$, packing switchover of $80 \%$, injection pressure of $1600 \mathrm{MPa}$, and packing pressure at second progressive stroke of $800 \mathrm{MPa}$, resulting in $50.74 \mathrm{MPa}$ hoop tensile strength, $4.89 \%$ elongation at break, and $0.0075 \%$ shrinkage. Statistical analyses 
TABLE 7: ANOVA table for shrinkage in optimization experiment.

\begin{tabular}{lccccc}
\hline Column & Parameter & DOF & Sum of squares & Variance & $F$ \\
\hline$A$ & Melt temperature & 2 & 198.28 & 99.14 & 21.39 \\
$B$ & Packing switchover & 2 & 167.62 & 83.81 & 18.08 \\
$C$ & Injection pressure & 2 & 505.17 & 252.58 & 54.49 \\
$D$ & Packing pressure 2 & 2 & 56.07 & 28.04 & 6.05 \\
& All others/error & 0 & & & $\mathbf{1 0 0 . 0 0}$ \\
& Total & $\mathbf{8}$ & $\mathbf{9 2 7 . 1 4}$ & & \\
\hline
\end{tabular}

TABLE 8: ANOVA table for multiple quality characteristics in optimization experiment.

\begin{tabular}{|c|c|c|c|c|c|c|}
\hline Column & Parameter & DOF & Sum of squares & Variance & $F$ & Percent \\
\hline$A$ & Melt temperature & 2 & 3.214 & 1.607 & & 62.13 \\
\hline$B$ & Packing switchover & 2 & 0.673 & 0.337 & & 13.01 \\
\hline C & Injection pressure & 2 & 0.922 & 0.461 & & 17.83 \\
\hline \multirow[t]{3}{*}{$D$} & Packing pressure 2 & 2 & 0.364 & 0.182 & & 7.03 \\
\hline & All others/error & 0 & & & & \\
\hline & Total & 8 & 5.173 & & & 100.00 \\
\hline
\end{tabular}

TABLE 9: Comparison of product performance for virgin ABS and R-40 before and after optimization.

\begin{tabular}{lccc}
\hline Criteria & $\begin{array}{c}\text { Hoop tensile } \\
\text { strength }(\mathrm{MPa})\end{array}$ & $\begin{array}{c}\text { Elongation at } \\
\text { break }(\%)\end{array}$ & $\begin{array}{c}\text { Shrinkage } \\
(\%)\end{array}$ \\
\hline $\begin{array}{l}\text { Virgin ABS } \\
\text { R-40 before }\end{array}$ & 50.22 & 3.81 & 0.0985 \\
$\begin{array}{l}\text { optimization } \\
\text { R-40 after }\end{array}$ & 49.28 & 3.74 & 0.1123 \\
optimization & 50.74 & 4.89 & 0.0075 \\
\hline
\end{tabular}

based on the main effects and ANOVA of the Taguchi method appropriately characterized the effect of different processing parameters on multiple quality characteristics. Among the parameters selected in the optimization experiment, melt temperature was found to be the most decisive factor simultaneously affecting the hoop tensile strength, elongation at break, and shrinkage of the injection-moulded ring stopper.

\section{References}

[1] T. Chilton, S. Burnley, and S. Nesaratnam, "A life cycle assessment of the closed-loop recycling and thermal recovery of postconsumer PET,' Resources, Conservation and Recycling, vol. 54, no. 12, pp. 1241-1249, 2010.

[2] D. Froelich, E. Maris, N. Haoues et al., "State of the art of plastic sorting and recycling: feedback to vehicle design," Minerals Engineering, vol. 20, no. 9, pp. 902-912, 2007.

[3] K. Butler, "Recycling of molded SMC and BMC materials," in Proceedings of the 46th Annual Technical Conference, Reinforced Plastics/Composites Institute, Session 18B, pp. 1-8, The Society of the Plastics Industry, Inc, 1991.

[4] J. M. Pérez, J. L. Vilas, J. M. Laza et al., "Effect of reprocessing and accelerated weathering on ABS properties," Journal of Polymers and the Environment, vol. 18, no. 1, pp. 71-78, 2010.

[5] E.-K. Karahaliou and P. A. Tarantili, "Stability of ABS compounds subjected to repeated cycles of extrusion processing,"
Polymer Engineering and Science, vol. 49, no. 11, pp. 2269-2275, 2009.

[6] J. Lozano-Gonzáles Ma, T. Rodriguez-Hernandez Ma, E. A. Gonzales-De Los Santos, and J. Villapando-Olmos, "Physicalmechanical properties and morphological study on nylon-6 recycling by injection molding," Journal of Applied Polymer Science, vol. 76, pp. 851-858, 2000.

[7] G. M. Russo, V. Nicolais, L. Di Maio, S. Montesano, and L. Incarnato, "Rheological and mechanical properties of nylon 6 nanocomposites submitted to reprocessing with single and twin screw extruders," Polymer Degradation and Stability, vol. 92, no. 10, pp. 1925-1933, 2007.

[8] F. La Mantia, Handbook of Plastics Recycling, Rapra Technology Limited, Shrewsbury, UK, 2002.

[9] J. Pospíšil, F. A. Sitek, and R. Pfaendner, "Upgrading of recycled plastics by restabilization-an overview," Polymer Degradation and Stability, vol. 48, no. 3, pp. 351-358, 1995.

[10] F. P. La Mantia and M. Morreale, "Green composites: a brief review," Composites A, vol. 42, no. 6, pp. 579-588, 2011.

[11] I. M. Chen, T. M. Yeh, and C. T. Wu, "Reuse of wasted fiber reinforced plastics in thermoplastic composites," in Proceedings of the 49th Annual Technical Conference (ANTEC'91), pp. 21622166, May 1991.

[12] M. G. Segatelli, I. V. P. Yoshida, and M. D. C. Gonçalves, "Natural silica fiber as reinforcing filler of nylon 6," Composites B, vol. 41, no. 1, pp. 98-105, 2010.

[13] N. T. Phuong, V. Gilbert, and B. Chuong, "Preparation of recycled polypropylene/ organophilic modified layered silicates nanocomposites part I: the recycling process of polypropylene and the mechanical properties of recycled polypropylene/organoclay nanocomposites," Journal of Reinforced Plastics and Composites, vol. 27, no. 18, pp. 1983-2000, 2008.

[14] E. Ramírez-Vargas, Z. Sandoval-Arellano, J. S. HernándezValdez, J. G. Martínez-Colunga, and S. Sánchez-Valdés, "Compatibility of HDPE/postconsumer HDPE blends using compatibilizing agents," Journal of Applied Polymer Science, vol. 100, no. 5, pp. 3696-3706, 2006.

[15] Y. K. Shen, J. J. Liu, C. T. Chang, and C. Y. Chiu, "Comparison of the results for semisolid and plastic injection molding process," 
International Communications in Heat and Mass Transfer, vol. 29, no. 1, pp. 97-105, 2002.

[16] N. M. Mehat and S. Kamaruddin, "Investigating the effects of injection molding parameters on the mechanical properties of recycled plastic parts using the Taguchi method," Materials and Manufacturing Processes, vol. 26, no. 2, pp. 202-209, 2011.

[17] P. K. Bharti and M. I. Khan, "Recent methods for optimization of plastic injection molding process-a retrospective and literature review," International Journal of Engineering Science and Technology, vol. 2, no. 9, pp. 4540-4554, 2010.

[18] K.-M. Tsai, C.-Y. Hsieh, and W.-C. Lo, "A study of the effects of process parameters for injection molding on surface quality of optical lenses," Journal of Materials Processing Technology, vol. 209, no. 7, pp. 3469-3477, 2009.

[19] F. Shi, Z. L. Lou, J. G. Lu, and Y. Q. Zhang, "Optimisation of plastic injection moulding process with soft computing," International Journal of Advanced Manufacturing Technology, vol. 21, no. 9, pp. 656-661, 2003.

[20] H. Kurtaran, B. Ozcelik, and T. Erzurumlu, "Warpage optimization of a bus ceiling lamp base using neural network model and genetic algorithm," Journal of Materials Processing Technology, vol. 169, no. 2, pp. 314-319, 2005.

[21] B. Ozcelik and T. Erzurumlu, "Comparison of the warpage optimization in the plastic injection molding using ANOVA, neural network model and genetic algorithm," Journal of Materials Processing Technology, vol. 171, no. 3, pp. 437-445, 2006.

[22] H. B. Daly, K. T. Nguyen, B. Sanschagrin, and K. C. Cole, "The build-up and measurement of molecular orientation, crystalline morphology, and residual stresses in injection molded parts: a review," Journal of Injection Molding Technology, vol. 2, no. 2, pp. 59-85, 1998.

[23] Y. Wang, H. Zou, Q. Fu, G. Zhang, and K. Shen, "Super polyolefin blends achieved via dynamic packing injection molding: tensile strength," Journal of Applied Polymer Science, vol. 85, no. 2, pp. 236-243, 2002.

[24] D. Zhang, C. Sun, J. Beard, H. Brown, I. Carson, and C. Hwo, "Development and characterization of poly(trimethylene terephthalate)-based bicomponent meltblown nonwovens," Journal of Applied Polymer Science, vol. 83, no. 6, pp. 1280-1287, 2002.

[25] T. C. Chang and E. Faison III, "Shrinkage behavior and optimization of injection molded parts studied by the Taguchi method," Polymer Engineering and Science, vol. 41, no. 5, pp. 703-710, 2001.

[26] S. M. Mousavi, S. A. Shojaosadati, J. Golestani, and F. Yazdian, "CFD simulation and optimization of effective parameters for biomass production in a horizontal tubular loop bioreactor," Chemical Engineering and Processing, vol. 49, no. 12, pp. 12491258, 2010.

[27] R. K. Roy, Design of Experiment Using the Taguchi Approach: 16 Steps to Product and Process Improvement, John Wiley and Sons, New York, NY, USA, 2001. 

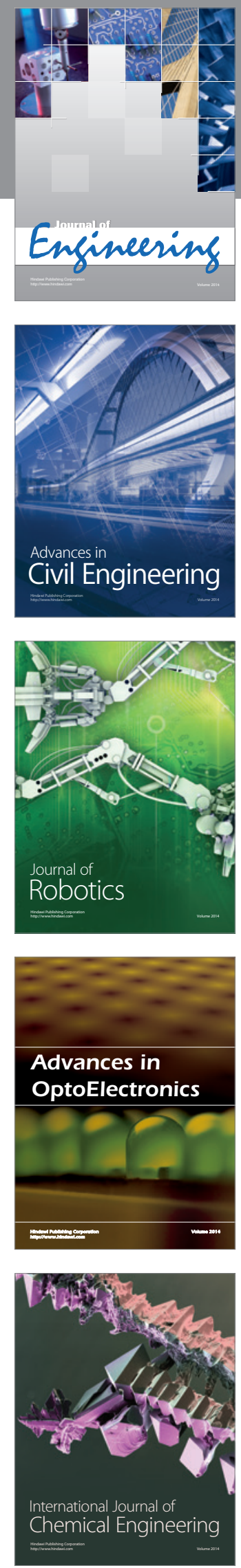

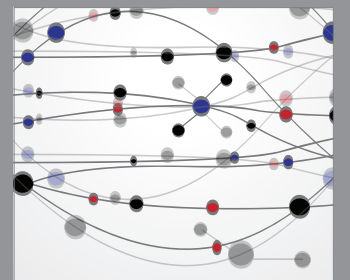

The Scientific World Journal
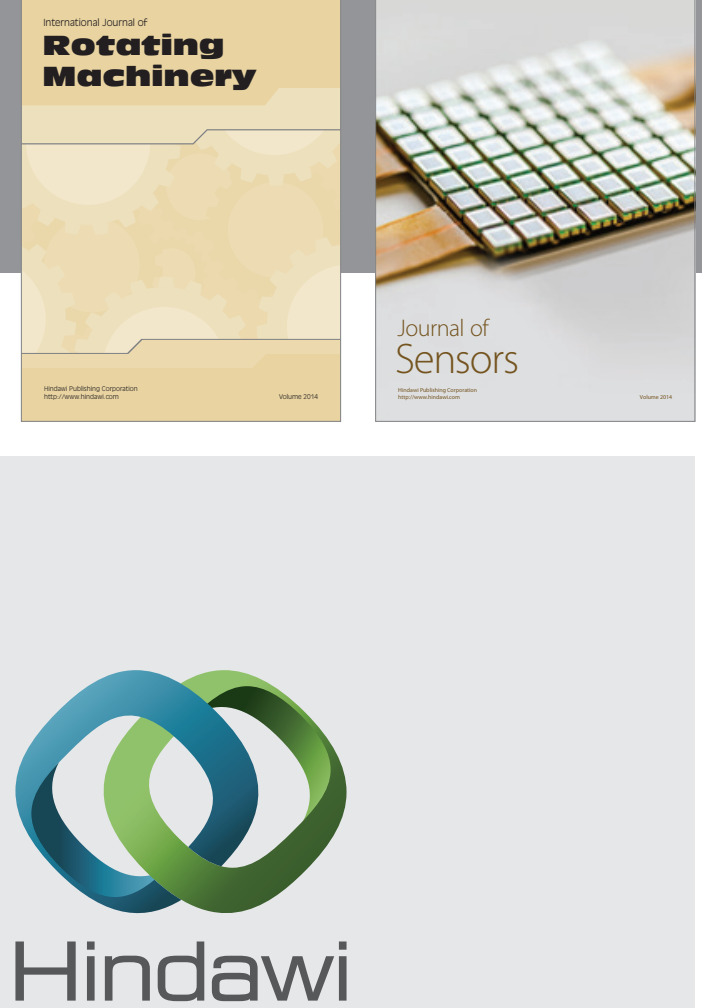

Submit your manuscripts at http://www.hindawi.com
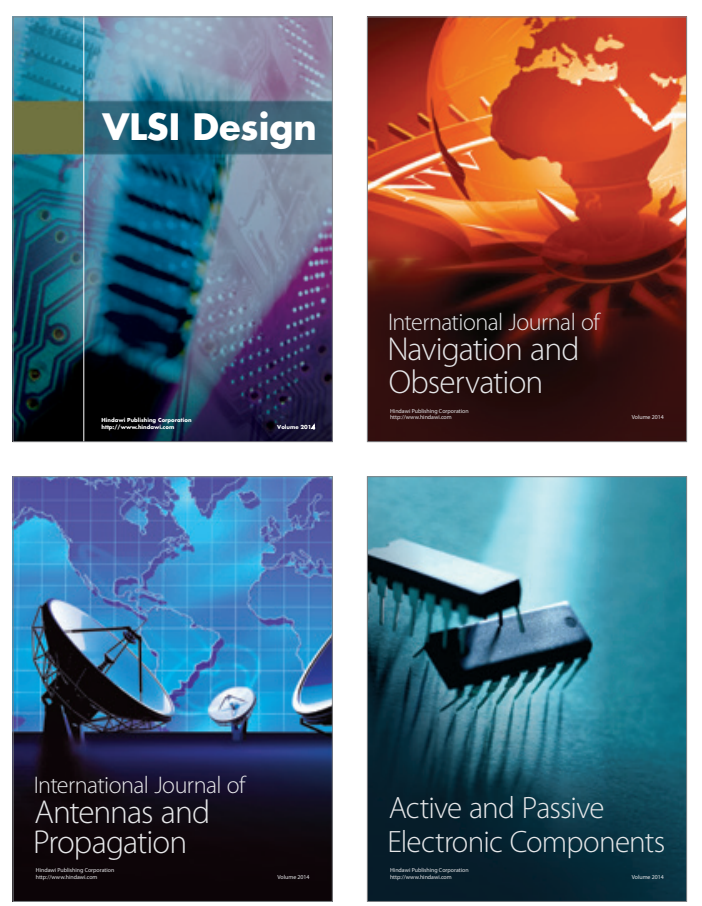
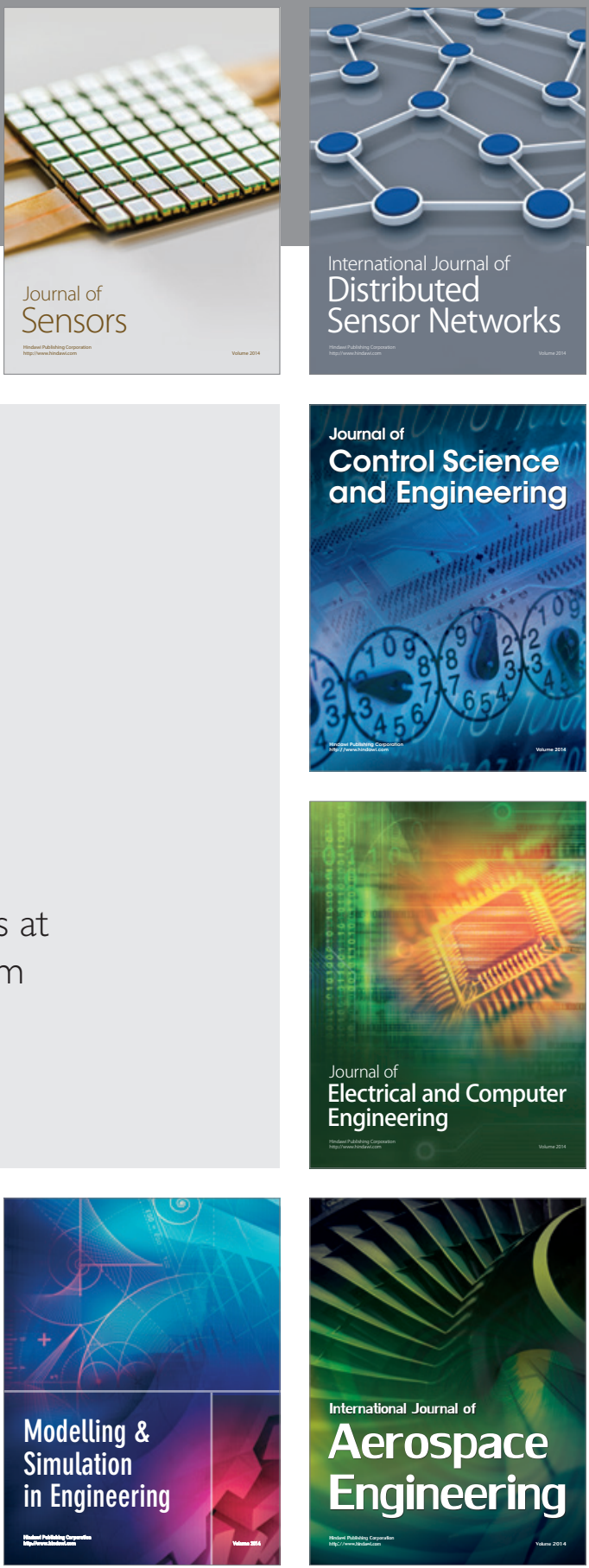

Journal of

Control Science

and Engineering
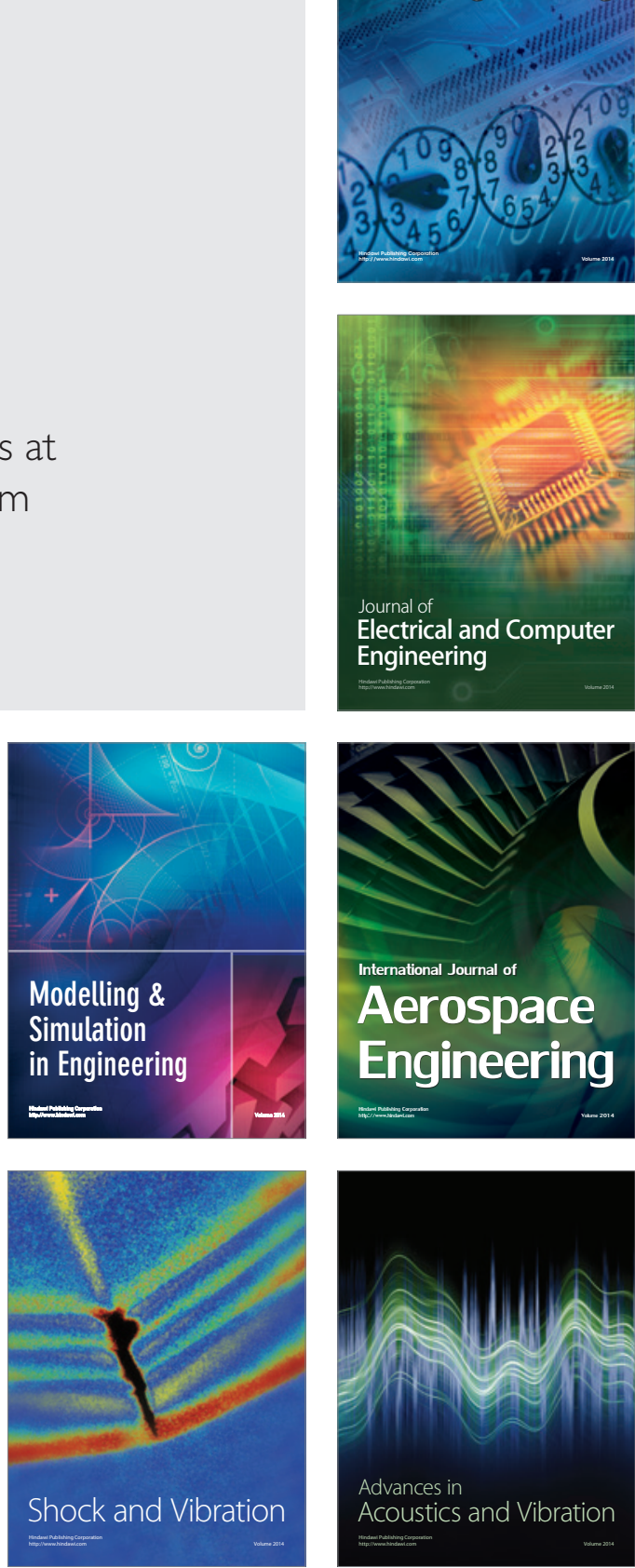